INTERNATIONAL BULLETIN OF BACTERIOLOGICAL NOMENCLATURE AND TAXONOMY

Volume 8 No. 2

pp. 93-95

\title{
SUPPLEMENT TO THE \\ THIRD REPORT ON THE SHIGELLA GROUP
}

The Enterobacteriaceae Subcommittee of the Nomenclature Committee of the International

Association of Microbiological Societies ${ }^{1}$

In the 1953 Subcommittee Report (Internationa 1 Bulletin. $4: 90-94$. 1954), it was recommended that certain sub judice Shigella serotypes be considered for possible future addition to the Shigella schema. Since the 1953 Report was prepared these sub judice serotypes have been studied by various investigators and additional cultures of several have been isolated and studied. Therefore, it is recommended that certain of these serotypes be given serotype designations and added to the Shigella schema in the proper subgroup. Serotypes 58 (Cox) and 2050-52 may be added to subgroup A (Shigella dysenteriae) as serotypes 9 and 10, respectively, and serotypes $123,425,2770-51$, and 703 may be added to subgroup C (Shigella boydii) as serotypes 12, 13, 14, and 15, respectively (see Shigella schema, appended). Further, it is recommended that the status of serotype 3873-50 and certain other serotypes remain sub judice for the present.

Three subserotypes of Shigella flexneri 3 are listed in the schema attached to the main body of the Third Report on the Shigella group as well as in that appended hereto. A characterization of these follows: subserotype 3 a corresponds to the classical $\mathrm{Z}$, which possesses group factors (subsidiary antigens) 6 and 7,8 but lacks the 3,4 ( $Y$ ) component; subse rotype $3 b$ contains the 3,4 factor in addition to factors 6 and 7,8 ; and subserotype $3 c$ possesses group factor 6 , but lacks 3,4 and 7,8 . All possess the same type or main antigen (III).

\section{REFERENCES}

Serotype 58

Cox, C.D. and G.I. Wallace 1948 .

J. Immunol. 60:465.

Internat1. Bull. Bact. Nomen. and Tax. $\underline{8}(1): 25-70.1958$. 
Page 94

I NTERNATIONAL BULLETIN

Se rotypes 123, 3873-50, $2770-51$ and 425

Serotype 703

Serotype $2050-52$

Above serotypes (and certain sub judice serotypes)
Ewing, W.H. and M.C. Hucks. 1952. J. Immunol. 69:575.

Ewing, W.H., M.C. Hucks and M.W. Taylor. 1952. J. Bact. 63: 319.

Ewing, W.H. 1953. J. Bact. 666: 333.

Ewing, W. H., R. W. Reavis, and B.R. Davis. 1958. Canad. J. Microbiol., in press. 
Page 95

B A C T ERIOLOGICAL NOMENCLATURE A N D T A X ONOMY

Shigella Taxonomy and Nomenc lature

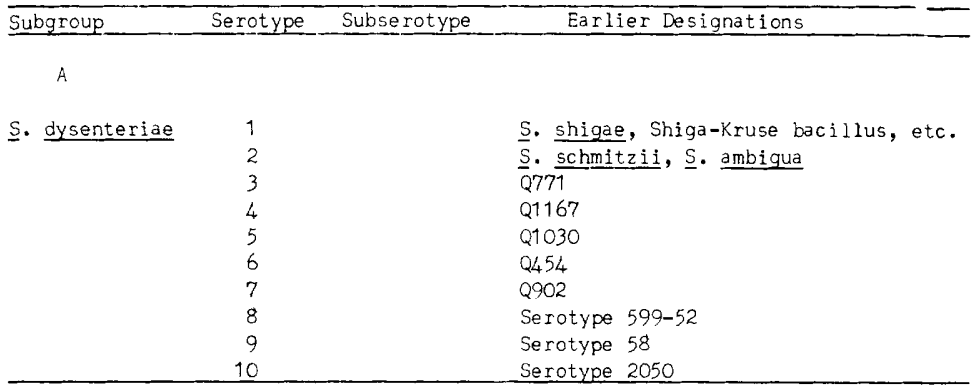

B

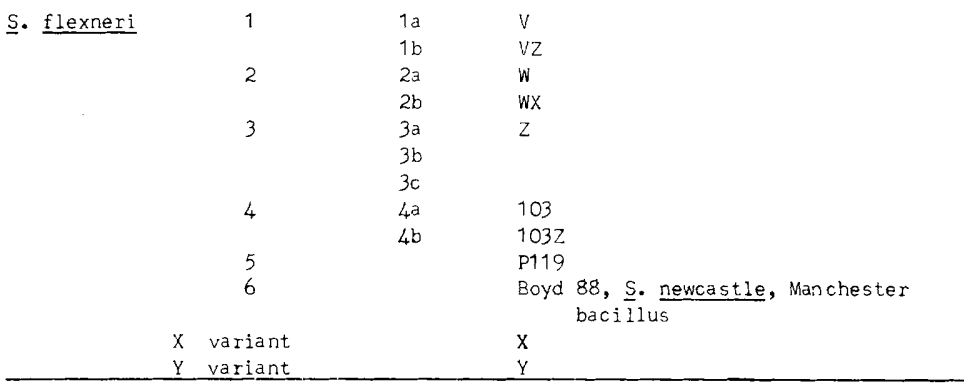

C

S. boydii

S. boydii
2
3
4
5
6
7
8
9
10
11
12
13
14
15

D

S. sonnei

Sonne-Duval, Sonne III, etc. 
